\title{
Sistema de solución de los conflictos de leyes en materia de trabajo
}

\author{
Por: el Dr. LUIS FUENTES VILLARAN
}

\section{INTRODUCCION}

Los sistemas propuestos para solucionar los conflictos de leyes en materia de trabajo son numerosos. Constituyen, pese a la corta vida de esta disciplina, una gama de criterios que han veniảo sucediéndose en el tiempo y en el espacio. Pocos son los asuntos de Derecho Internacional Privado que puedan jactarse de contar con una variedad tan rica de soluciones. Todos estos sistemas, que analizaremos, se encuentran debidamente fundados en argumentos tanto jurídicos como prácticos, aunque, desde luego, en algunos las bases son más sólidas que en otros. Sin embargo, es de lamentar que ninguno de ellos alcance la perfección, por cuanto al lado de las ventajas que ofrecen, no faltan los inconvenientes.

Adelantando alguna idea, diremos que la solución adecuada a los diferentes tipos de problemas que se presentan en Derecho Internacional Privado del Trabajo no podrá ser una y la misma para todos, sino que será necesario poner en práctica la máxima de que a diversidad de problemas, corresponde aplicar diversidad de soluciones.

No obstante, es posible señalar determinadas pautas que servirán de guía para arribar a la solución ideal. Estas pautas son fundamentalmente dos:

$1^{\circ}$. - Intentar que la relación de trabajo quede sujeta a solo una legislación; $y$

$2^{\circ}$.- Que dicha legislación, sea la más adecuada para regir la relación jurídico-laboral.

El primer requisito tiene por objeto impedir la desmembración del contrato de trabajo y evitar que una misma relación laboral quede gobernada por dos o más legislaciones, que pueden ser contradictorias.

El segundo requisito es complemento del anterior. Responde a la necesidad de que las normas que se apliquen sean apropiadas. Nada se 
ganaría con asegurar el imperio de una sola legislación si ésta no es la debida.

Teniendo presente ambas consideraciones, pasamos a continuación a un estudio somero de cada sistema de solución en particular.

\section{SISTEMA DE LA LEY PERSONAL DE LAS PARTES}

Según este sistema, el contrato de trabajo, debe regirse por la ley personal de las partes contratantes, sea esta la ley de la nacionalidad, o la ley del domicilio de los interesados. Es en atención a esta distinción que el sistema de la ley personal debemos estudiarlo bajo la sub-división siquiente:

\section{A. - SISTEMA DE LA LEY DE LA NÄCIONALIDAD DE LAS PARTES.}

Este sistema propugna la aplicación, a la relación de trabajo, de la ley del país del cual las partes son naturales.

Su fundamento lo encontramos en la docirina de la personalidad del derecho. Un Estado no legisla para un territorio, sino para un pueblo. Las leyes de un Estado recaen sobre sus nacionales y sobre los actos de éstos cualquiera que seo el lugar en donte estén.

Hoy por hoy, este argumento es de escaso valor, por cuanto la teoría de la personalidad del derecho, en que se basa, está superada. La doctrina imperante actualmente preconiza la territorialidad del derecho, no sólo en materia de Dexecho de Trabajo, sino aún en cuestiones de Derecho Común. En la época en que vivimos los Estados ejercen su imperio sobre todos los individuos que habitan dentro de su suelo, sean éstos nacionales o extranjeros y sus leyes rigen normalmenie dentro de su dominio territorial.

Se argumenta que la ley nacional de los contraiantes es la que mejor conocen los mismos. En consecuencia, resulta lógico y conveniente aplicar dicha ley, pues es de presumir a ialta do manifestación en contrario, que fué su deseo someterse a la ley con la cual están más familiarizados: la de su común nacionalidad.

Esta razón sería válida si abonase exclusivamente al sistema de la ley nacional de las partes, pero resulta que la ley elegida por las partes. la ley del domicilio, la ley del lugar de ejecución, la ley del lugar de celebración, etc., pueden ofrecer igual ventaja.

Se dice también que el sistema de la ley de la nacionalidad hace más remota la ocasión de que las partes incurrán en fraude a la ley.

Pero si bien es cierto que resulta más difícil de lograr un cambio fraudulento de nacionalidad, con relación a la simulación de domicilio o del lugar de celebración del contrato, siempre subsiste la posibilidad de una adopción traudulenta de ciudadanía.

El obstáculo más grave que se opone al sistema que estamos estudiando es que sólo puede funcionar cuando ambas partes de la relación 
laboral tienen la misma nacionalidad. De no ser así, tendría que aplicarse, a una misma relación, dos legislaciones distintas. Ello supondría que cada contratante dió su consentimiento de acuerdo con una ley diferente, lo cual es inadmisible dado que "es esencial a todo convenio que haya consentimiento común sobre todo lo que compone el contrato" (1)

Para resolver esta situación insólita, los defensores del sistema, afirman que en tal caso se debe elegir solo una ley, ya sea la del servidor, ya la del principal.

\section{a) SISTEMA DE LA LEY NACIONAL DEL SERVIDOR}

Considera esta corriente doctrinaria que, siendo el Derecho de Trabajo un conjunto de principios y normas protectoras del asalariado, la ley que debe regir el contrato de trabajo no puede ser otra que la nacional del trabajador.

Pero esta solución sería incompatible precisamente con el espiritu tutelar del Derecho de Trabajo en aquel supuesto en que la legislación nacional del patrón fuese más beneficiosa para el servidor.

Por otro lado, es fácil comprender las dificultades que se derivarian para el desarrollo comercial e industrial si cada empleador tuviese que regir sus relaciones con el personal sujetándose a la ley nacional de cada uno de sus empleados.

En cuanto a los trabajadores se refiere, esta solución lesiona la igualdad de trato a que tienen derecho todos los servidores de un mismo centro de trabajo.

\section{b) SISTEMA DE LA LEY NACIONAL DEL PRINCIPAL}

A fin de superar los defectós incurridos por el sistema de la ley nacional del servidor, se debe optar por el sistema de la ley nacional del principal.

Este sistema elimina algunas de las dificultades inherentes al sistema de la ley nacional del servidor, pero no por ello se encuentra exento de graves obstáculos.

Se arguye en su favor que el contrato de trabajo es un contrato de adhesión, o por lo menos, un contrato realizado sobre propuestas generales que sólo admite variaciones materiales, en el salario, fecha de iniciación de la prestación, plazo, etc.

Si esto es así, como en realidad parece serlo, es lógico pensar que una sola y misma ley debe regular el contrato de trabajo y esta no puede ser otra que la ley nacional del proponente, ya que no es razonable pen-

(1) Foelix, "Tratado de Derecho Internacional Privado". - Citado per Alfonsín. Q. "Nota sobre el Régimen de Contratos en Derecho Privado Internacional". Rev. Inst. Derecho Civil. Univ. Nac, Tucumán.- $1948 / 49$ pág. 95. 
sar que el proponente ofrezca contratar bajo la ley del aceptante, hasta entonces desconocido.

El argumento de que todos los contratos de adhesión o similares, entre los que suele ubicarse el contrato de trabajo, deben regirse por una sóla ley es irrefutable. Pero el que esa ley sea infaliblemente la nacional del proponente (léase principal) es una conclusión que no fluye necesariamente de las premisas expuestas.

Antes bien, este sistema se presta a los inconvenientes que traen consigo el hecho que el empleador cambie de nacionalidad. Pero si esto es de por sí ya suficiente para traer trastornos, más grave es el caso, perfectamente factible, de que el principal carezca de nacionalidad, o que tenga dos o más nacionalidades.

Por último, la ley nacional del principal, puede no tener mayor interés en regular una relación laboral determinada. Tal sería el caso de un contrato de trabajo celebrado en el Perú, para ser ejecutado en este país, en el cual el empleador sea un alemán residente en el Perú y el servidor un peruano domiciliado también en el Perú.

¿Podríamos sostener en este supuesto que la ley más aparente para regular esa relación laboral sea la alemana- Desde luego que no.- Es evidente que la legislación competente es la peruana y no la germana, a la que mayormente no puede afectar esta coyuntura. Los elementos de conexión (nacionalidad y domicilio del servidor, domicilio del empleador, lugar de celebración y ejecución del contrato) hacen grevitar sobre la relación laboral la legislación del Perú. La atracción de estos elementos es mucho más poderosa que la ejercida por la nacionalidad del principal.

\section{B - SISTEMA DE LÄ LEY DEL DOMICILIO DE LAS PARTES.}

De conformidad con este sistema, la ley competente para regir el contrato de trabajo es la ley del domicilio de las partes.

Se funda este sistema, en que, positivamente, es un principio consagrado que el estado y la capacidad de las personas, entre otras cosas, se encuentran sometidos a la ley del domicilio.

Es de presumir, además, que la ley que mejor conocen los contratantes es la vigente en la localidad de su domicilio.

Por otro lado, el domicilio suele coincidir con el lugar de celebración y ejecución del contrato, así como también con el lugar del fuero al que habría que recurrir para dirimir cualquier diferencia.

Frente a estos argumentos en pro del sistema de la ley del domicilio de las partes, se oponen los siguientes obstáculos.

En primer lugar, el sistema en mención requiere para su cabal funcionamiento que ambas partes contratantes domicilien dentro de una misma jurisdicción. Si no fuera así, habría que decidirse por la ley de una u oira parte, ya que no es admisible aplicar a un mismo asunto dos legislaciones, que pueden ser contradictorias.

En segundo lugar, afirmar que la ley que mejor conocen los contratantes es la de su domicilio, no constituye una regla absoluta. Puede suce- 
der que una $\mathrm{u}$ otra parte haya trasladado recientemente su domicilio a una nueva localidad, que es precisamente el caso en que se encontrarían los trabajadores migrantes, en cuyo supuesto es dable presumir todo lo contrario. Vale decir que no están familiarizados con la ley de su domicilio.

A mayor abundamiento, se comenta que el domicilio es un criterio inestable. Puede suceder, y de hecho sucede, que las partes tengan más de un domicilio. Nuestro Código Civil sanciona legalmente la pluralidad de domicilios, al establecer en su art. $20^{\circ}$ que "Si una persona vive alternativamente, o tiene ocupaciones habituales en varios lugares se considerará domiciliada en cuulquiera de ellos". Si estos domicilios están ubicados en diferentes países, no podríamos evitar que sobre la relación jurídicas concurriesen varias legislaciones.

Así mismo, resulta sumamente fácil mudar de domicilio. Esta libertad acarrea una serie de trastornos desde el punto de vista jurídico, aún en el supuesto de que el cambio se realice inocentemente, sin intención de defraudar a la ley.

Por último, el que el domicilio coincida con el lugar de celebración del contrato, o con el lugar de ejecución del mismo, o con el asiento del foro competente, tampoco constituye razón que engrose el caudal de la arqumentación en favor del sistema de la ley del domicilio de las partes. En efecto, estas coincidencias no se dan siempre, y cuanto se realizan, cabe pensar si la ley del domicilio es la pertinente por ser tal, o lo es acaso por ser la ley del lugar de la celebración, o de la ejecución, o la del foro competente.

For todas estas consideraciones el criterio del domicilio resulta inadecuado en Derecho Internacional Privado del Trabajo para adoptarse como el principio general, pese $\alpha$ que en Derecho Internacional Privado Común éste constiluye la vinculación primaria.

\section{a) SISTEMA DE LA LEY DEL DOMICILIO DEL SERVIDOR.}

No falta quien sostenga que todo contrato de trabajo debe sujetarse a la ley del domicilio del servidor.

En favor y en contra de esta tésis cabe repetir, con las reservas propias del caso, los argumentos vertidos al referinos al sistema de la ley nacional del servidor $y$ al sistema de la ley del domicilio de las partes.

\section{b) SISTEMA DE LA LEY DEL DOMICILIO DEL PRINCIPAL.}

La ley del domicilio del principal o de la empresa, como suele llamársele, es la indicada para regir la relación laboral, por numerosas y fundadas razones.

Para Gottschalk, "la lex domicilii de la empresa corresponde, en el derecho del trabajo a la lex rei sitae en el derecho de las cosas. En contrato individual de trabajo no se concibe más sin colocarlo inmediatamen- 
te en el más intimo contacto con el conjunto de las relaciones humanas que, espontanea y automáticamente, nacen de la organización y división del trabajo colectivo en la empresa". (2)

En efecto, citando a Devealí, "la empresa puede, en cierta forma. ser considerada como una cosa - o una universitas rerum - destinada a funcionar como medio, fin u objeto de la prestación del trabajador".

En realidad, la empresa constituye el centro de actividades del negocio. Ella reune y orienta los esfuerzos individuales hacia la consecusión de los fines colectivos. La empresa requiere para la eficiente realización de su función coordinadora, directriz y ejecutiva el contar con un estatuto. único que garantice el ordenado y pacífico desarrollo de sus actividades. Los contratos individuales de trabajo deben, de esta suerte, conformarse a las normas dentro de las cuales se desenvuelven las operaciones de la empresa. Todo nuevo servidor no hace más que adherirse a la reglamentación preexistente, sea de manera expresa o tócita.

La argumentación es correcta. Si se da a escoger entre la ley personal del servidor y la ley del domicilio de la empresa, es esta última la que debe primar.

Pero, el asunto no se presenta tan claro cuando la elección es entre la ley del domicilio de la empresa y la ley del lugar de ejecución del trabajo.

En efecto, a la empresa interesa la aplicación de su estatuto para el felíz logro de sus objetivos. Pero contra ese interés particulor, muy respetable por cierto, encontramos el interés supremo del Estado de someter a sus normas los efectos de aquella relación jurídica laboral que tiene ejecución en su territorio. De entrar en pugna estos intereses se aplicaría la ley del lugar de la ejecución del contrato. Esta solución se desprende por su propio peso.

Sin embargo, la conclusión expuesta no es absoluta. Creemos que cuando el trabajo se realiza en forma permanente en un territorio, la ley aplicable es la del Estado en cuyo suelo se están ejecutando las labores. Pero hay casos en que es difícil precisar el lugar de ejecución de las mismas. Pensemos en los viajantes de comercio, en los trabajadores de transportes internacionales, o en los funcionarios encargados de la supervigilancia de las filiales de las grandes compañias internacionales, que están constantemente viajando de un país a otro con motivo de sus visitas de inspección. En todos estos casos opinamos que la ley competente debe ser la ley del domicilio de la empresa. Esta solución no tiene porque herir a los Estados que se sientan afectados por la misma. Recordemos que al definir el Derecho Internacional Privado del Trabajo le hemos asignado una tendencia a favorecer el desarrollo de las relaciones jurídico-laborales dentro de la sociedad universal. La ley del domicilio de la empresa satisface esta finalidad, en los casos citados y en otros similares, mejor que cual-

(2) Gottschalk E. F.- Ob. Cit., pág. 542 .

(3) Devealí, M., Ob. Cil., Pág. 78. 
quiera de los restantes sistemas de solución conocidos, lo que la convierte en la solución adecuada para los mismos.

Este principio ha encontrado su concreción en la ley polaca de 1926 en cuyo art. $8^{\circ}$ establece que a falta de determinación de las partes ha de tenerse como competente "en los contratos de trabajo, hechos for patronos con obreros o empleados, la ley de la sede de los establecimientos de comercio, industria o minas interesados" (4).

Así mismo, la ley argentina $\mathrm{N}^{\circ} 12789$, contiene disposiciones que permiten afirmar que está guiada por el principio de la lex domicilii de la empresa. Esia ley, "con el propósito de asegurar su aplicación efectiva en beneficio de los trabajadores contratados en los países vecinos", dispone en su art. 12 que "todo empresario intermediario o persona que contrate obreros en el extranjero, para realizar labores en el territorio del país, que sean de las comprendidas en esta ley, deberá fijar su domicilio en el mismo y cumplir con las disposiciones anteriormente mencionadas". (5)

Este sistema es considerado como muy conveniente para regular el trabajo en ciertos transportes internacionales. Cesarino Junior y Mario Devealí, citando ambos a Kroheim, nos dicen que "el trabaio de la gente del aire debe seguir forzosamente el mismo régimen internacional como si el avión no saliera del país donde la compañía está domiciliada. La actividad del personal en el exterior no es más que una extensión, que una prolongación de su trabajo ejecutada sobre el territorio nacional". (6) Lo cual importa en nuestro concepto una aplicación de la ley del pabellón.

En Alemania esta solución ha sido muy bien recibida, habiendo desarrollado los juristas germanos le teoría del "Ausstrahlungen". de confor. midad con esta doctrina, se ha aplicado la ley alemana a los servidores del ferrocarril alemán que prestan sus servicios en la estación de Basilea, en territorio Suizo. (7).

En el campo de los acuerdos internacionales encontramos los siguientes instrumentos que adoptan el sistema de la ley del domicilio de la empresa: el art. 13\% (B) del Proyecto de Convención Europea sobre Seguridad Social de Trabajadores Migrantes, el art. $4^{\circ}$ del Acuerdo sobre Seguridad Social de los Lancheros del Rhin y el art. $2^{\circ}$ de la Convención Europea sobre Seguridad Social de los Trabajadores en Transportes Internacionales.

En resumen: el sistema de la ley del domícilio del principal resulta adecuado para regular las relaciones entre empleador y empleado cuando no puede determinarse con precisión el lugar de ejecución del trabajo. así como también cuando por razones pasajeras, el trabajo se efectúa en

(4) Gotlschalk, E. F., Ob. Cit. pág. 542 .

(5) Dereall, M.. Ob. Cit., pág. 84.

(6) Kroheim. "Les Conflits de Lois en Matiere de Contrat de Travail", París, 1939. págs. 139/140.- Citado por C. Junlor. "Leyes de Trabajo Aplicables a los Aeronarogantes": Rev. Derecho de Trabajo. Bs. Aires. 1947. T. VII. pág. 430; Y M. Devealí, "La Relación de Trabajo en Derecho Internacional Privado", Rev. Derecho del Trabajo, Bs. Airos, 1952, T. VII, pág. 78.

(7) I. L. O.- Conflits of Laws in Labor Matters, Genera, 1957. pág. 80. 
el extranjero. Recordemos que el servidor, que es temporalmente trasladado al exterior, continúa siendo parte integrante de la empresa.

\section{SISTEMA DE LA LEY ELEGIDA FOR LA VOLUNTAD DE LAS PARTES}

El sistema de la ley elegida por la voluntad de las partes - también denominado simplemente sistema de la voluntad de las partes - enuncia que no hay ley más apropiada para regir una relación laboral que la convenida por los contratantes.

Basándose en el principio filosófico de que las leyes se han hecho para los hombres, y no éstos para las leyes, se argumenta que corresponde a los hombres plena libertad para elegir, dentro de las muchas legislaciones, aquella que estimen conveniente. Nadie mejor que los propios interesados para determinar la ley que ha de regir su negocio.

Fero ante este planteamiento, en extremo liberal, "algunos juristas, como Van Berchem, han sostenido que tal facultad de las partes no es ilimitada, sino que se refiere exclusivamente a la ley nacional común, o de una de las partes, a la del lugar de la celebración del contrato, o la del lugar de ejecución, ya que no se puede obligar al Juez a seguir a las partes en sus más caprichosas referencias legislativas" (8).

Contra esta posición, que podríamos clasificar de intermedia - entre la autarquía personal absoluta y la heteremonía legal absoluta - se critica que si se permite a las partes contratar y establecer así las condiciones a que someten sus obligaciones recíprocas, no se comprende porqué ha de limitarseles la facultad de escoger ley.

La teoría de la libre elección de la ley se encuentra confirmada, positivamente, por la Ley Federal Suiza, promulgada el 13 le Junio de 1941. sobre viajantes de comercio, que dispone en su art. $3^{\text {o }}$ inc. d) que "el contrato debe ser hecho por escrito" y deberá determinar "el derecho aplicable y la jurisdicción, cuando una de las partes se domicilie en el extran"jero".

La jurisprudencia alemana se ha manifestado abiertamente por el sistema de la ley elegida por la voluntad de las partes. Los tribunales de esla nación han hecho honor a los pactos privados estableciendo una ley competente, y a falta de claúsula expresa, han indagado par la intención tácita de los contratantes, aplicando, al respecto, lo que pudiera considerarse la voluntad presunta de las partes.

En similar sentido se han pronunciado las Cortes inglesas y escocesas. Para dichos tribunales corresponde, en primerisimo lugar, a los propios interesados elegir la ley bajo la cual quieren sujetar su negocio. En materia de contratos de trabajo las normas de Derecho Internacional Frivado se aplican de igual manera que los contratos de derecho común. En este aspecto, se puede afirmar que la libertad de que gozan las partes de

(8) Van Berchem, Citado por Devealí, M. Ob. Cit., páf. 74. 
elegir la ley competente es reconocida sin reserva por los jueces de Gran Bretaña y Escocia.

En Francia y en Estados Unidos de América, se encuentran también fallos en el sentido de que a las relaciones de trabajo, en las que intervie. ne un elemento extranjero, corresponde aplicar la ley convenida por los contratantes, siguiendo así la regla común para todos los contratos en general.

Como se puede apreciar, este sistema ha sido acogido mayormente por países sajones. En cambio, los países de origen latino, dentro de los cuales destaca Italia, no admiten como vinculación primaria la ley elegida por las partes. Antes bien, en atención a la naturaleza especialísima del contrato de trabajo, aplican al mismo la ley del lugar de ejecución de los servicios. Así, de ccuerdo con una decisión de la Corte de Casación, quedó categóricamente excluída la posibilidad de que las partes conviniesen válidamente en someterse a otra ley que no fuera la italiana, para un trabajo a realizarse en Italia. (9)

Sin embargo, la tendencia de los tribunales italianos parece indicar que cuando los servicios han de prestarse en el extranjero, el asunto se resuelve de conformidad con las reglas de Derecho Internacional Privado Común, es decir, respetando la voluntad de las partes. Pero, cuando el trabajo ha de efectuarse en territorio itálico, la ley de Italia es única y exclusivamente competente.

El sistema de la voluntad de las partes, que estamos analizando, no es en realidad una solución muy apropiada para resolver los conflictos de leyes en Derecho Internacional Privado del Trabajo. La naturaleza tutelar del Derecho de Trabajo impide que bajo las apariencias de un trato libre y comunicativo la parte más poderosa imponga el sometimiento a una legislación laboral incipiente, pobre en disposiciones protectoras del asalariado.

Independientemente de ello, puede suceder que las partes convengan en sujetar sus relaciones $\alpha$ una ley que resulte del todo inadecuada. Tal sería el caso de un contrato celebrado en Argentina, entre un chileno y un francés, domiciliados en el Uruguay, para ser ejecutado en el Perú, en el cual se pactase aplicar la ley griega. Es evidente que el contrato del ejemplo carece de todo elemento de conexión, tanto objetivo como subjetivo, (salvo la declaración de voluntad) que lo vincule con la ley de Grecia. La legislación helénica en este caso no podría, a nuestro entender, regir el contrato de trabajo pasando sobre legisiaciones tan interesadas y aptas para ello, como la del lugar donde han de ejecutarse las labores, la nacional de las partes, la del lugar de celebración del contrato, o la del domicilio de las partes.

Por tal razón, si bien odmitimos que los interesados pueden remitirse a una ley cualquiera para los efectos de su relación obrero-patronal, no creemos que esa ley, por el simple mérito de ser la acordada por las par-

(9) 1. L, 'O.- Ob. Cit.- pág. 73. 
tes, constituya la vinculación primoria, y como tal, sus disposiciones se apliquen preferentemente a cualquier otra legislación, inclusive a la del lugar de ejecución del trabajo.

Al respecto, repetimos el concepto vertido al referinos a la institución de la autonomía de la voluntad. La ley acordada por los interesados sólo tiene aplicación en la medida autorizada por aquella legislación a la cual corresponde verdaderamente la competencia, según la gravitación de los diversos elementos de conexión involucrados. Las disposiciones de la ley convenida solo intervienen en calidad de mero aporte, que se suma, cuando no es incompatible, a las normas imperativas llamadas a gobernar el contrato en vista de la naturaleza del mismo y de los factores de conexión aludidos.

Aceptar el sistema de la ley elegida por la voluntad de las partes, en forma irrestricta, representaría dar un paso atrás, hacia el horrendo liberalismo económico de siglos pasados. Desastrozas serían, con seguridad, las consecuencias que se derivarian de la aplicación en el ámbito internacional, de una fórmula retrógrada semejante a "laisser faire, laisser passer", ya superada en derecho intemo.

\section{SISTEMA DE LA LEX FORI}

Se define como aquel sistema que recomienda la aplicación, a la relación laboral, de la ley del país al cual pertenece la autoridad judicial que conoce del reclamo.

Quienes propugnan esta solución parten del principio de que el derecho substancial solo debe sar aplicado por el juez del Estado cuyas leyes gobiernen la relación laboral.

"Creemos que no sólo es evidentemente útil, sino necesario que el derecho substancial sea aplicado por el magistrado que mejor lo conoce, es decir, por aquel del Estado cliyas leyes rigen la relación laboral". (10)

Esta concepción tiene, sin duda alguna, la ventaja de evitar las consecuencias derivadas de fallos emitidos por jueces que se ven en el apuro de aplicar una legislación extranjera que ignoran, pudiendo fácilmente in. currir por ello en lamentables errores.

Sin embargo, este sistema es objetable por cuanto restringe la libertad de las partes de someterse al fuero que resulte más cómodo para ellas, respetando,se comprende, las limitaciones procesales propias del caso.

En el orden práctico y por razones de economía procesal, conviene ai servidor recurrir a los jueces de su localidad. Tal sería el caso si el fuero competente quedare muy distante de su residencia habitual.

Las dificultades que de hecho representa para el servidor el verse precisado $\alpha$ interponer $y$ proseguir su reclamación ante un fuero remoto, puede convertir en ilusorio su derecho al amparo de los tribunales de

(10) Lanfranchi, C.- Ob. Cit., pág. 217. 
justicia. Y si esto es así, con un trabajador nacional, mucho más grave se torna la objeción cuando está de por medio un trabajador migrante.

Pero si nos determinamos aquí y profundizamos un poco sobre las disquisiciones expuestas, veremos que presuponen la existencia de una ley competente, determinada evidentemente por un criterio distinto al del foro. En consecuencia, este sistema se desautoriza a sí mismo, como solución apta para elegir la ley aplicable a la relación laboral.

Por otro lado, en respaldo del sistema de la lex fori, "se ha sostenido que en virtud del caracter de orden público que tiene la legislación del trabajo, el juez no puede aplicar una ley extranjera". (11).

Esta afirmación queda refutada por los argumentos vertidos al estudiar la figura del orden público. En primer lugar, hemos clemostrado que no todas las normas de Derecho de Trabajo son de orden púbilico. En segundo término, hemos aclarado que, dada la inderogabilidad relativa, caracter especial del orden público en materia de trabajo, está permitida la aplicación de una norma foranea cuando la misma es más favorable al servidor. Es falso, pues, que el orden público elimine toda ingerencia de la ley extranjera en materia laboral. Ella rige, dentro de los límites trazados por sl derecho local, que al admitirla en su estructura le da fuerza de derecho vigente $y$, como tal, de inexcusable aplicación para el juez nacional.

Pero el más serio reparo que enfrenta este sistema es que la solución que ofrece es sólo a posteriori. En efecto, de acuerdo a este planteamiento, la ley competente sólo se descubriría en el momento de recurrir al Poder Judicial. Con anterioidad a este instante, las relaciones laborales quedarían libradas a la más profunda incertidumbre. No habría modo de conocer, a ciencia cierta, a que ley atenerse, puesto que en definitiva se aplicaría la leqislación del foro al que eventualmente se recurra.

\section{SISTEMA DE LA LEY DEL LUGXR DE LA CEIESPACION DEL CONTRATO}

De acuerdo con este sistema corresponde aplicar a la relación laboral la ley del lugar de la conclusión del acuerdo.

Se argumenta que "la celebración es el acto primordial en la vida del contrato: es lo primero en el orden cronológico y lo más importante en el orden lógico, puesto que de la celebración depende la existencia del contrato y su futura ejecución". (12) Lo que equivale a decir que entre celebración y ejecución hay una dependencia de causa a efecto. Pero esta afirmación, aparentemente cierta, se desmorrona si se plantea el asunto de la relación entre celebración $y$ ejecución como la vinculación habida entre medio $y$ fin.

Desde el punto de vista jurídico, la doctrina de la territorialidad del derecho, en voga actualmente, propugna que todos los convenios que se

(11) Gaete Berrios. A.- Ob. Cit., pág. 116.

(12) Alfonsin, ".- Ob. Cit., pág. 105. 
concluyan dentro del territorio de un Estado deben quedar sometidos a lus leyes de ese Estado. Luego, hemos de admitir que la ley del lugar de la ce-lebración del contrato es la competente para regir el mismo.

Pero si así tuese, invocando precisamente la teoría de la teritorialidad del derecho, mayores razones hay para aplicar la ley del Estado donde han de ejecutarse los servicios, en vez de la ley del país donde se ce-lebró el contrato.

En tercer lugar, se dice que el sistema de la lex loci contractus es única, nunca faita y es fija. (13) Es única, poŕque el contrato se celebra en un solo sitio; nunca falta, por cuanto necesariamente ha de celebrarse en algún lugar; y es fija, por cuanto pese a las vicisitudes por las que atraviese el contrato, el lugar de celebración permanece siempre el mismo.

El que sea única es una ventaja bastante apreciable, pero no basta para el caso. La ley competente no solo debe ser única sino, especialmente, adecuada. Y clesde la primera impresión la ley del lugar de la celebración se percibe como solución inaparente. "Si dos personas celebran dos contratos idénticos..., no es razonable que uno de esos contratos quede sujeto a la ley uruguaya por haberse consentido unos pasos para acá de la frontera; $y$ el otro quede sujeto a la ley brasileña por haberse consentido unos pasos mós allá. Siendo iguales los contratos, el régimen de ellos debe ser igual. La suerte de cada uno no puede ser echada, pues, consultando un dato exterior a su contenido, como lo es el lugar donde se celebró, $y$ sin consultar, en cambio, otro dato substancial: el lugar donde se han de cumplir las obligaciones contraídas". (14)

También es verdad que el contrato siempre ha de celebrase en algún lugar. Pero en realidad, el problema no consiste en eso. La cuestión reside en identificar fácilmente dicho lugar. Y esto no siempre se consigue bajo el sistema que estamos tratando. Pensemos en aquellos casos en que el contrato se concluye entre ausentes, 0 a bordo de un vehículo internacional en viaje. (15).

Independientemente del hecho que la ley de la celebración resulta impropia para gobernar la relación laboral, dado que el contrato pudo haberse concluído en una lacalidad en forma puramente accidental, se presenta la circunstancia de que el lugar de la celebración queda librado al arbitrio de las partes, confundiéndose, en sus consecuencias, este sistema con la teoría de la autonomía de la voluntad.

No obstante lo expuesto, el sistema de la ley del lugar de la celebración del cóntrato fué seguido por los tribunales de Suiza desde 1892. En Francia, dicha solución fué aceptada por el Tribunal de Rennes el año 1902 y por la Corte de Casación, según fallo del 26 de mayo de 1921, (affaire Antipoul), en el que se sostuvo que los accidentes del trabajo se relacionun

(13) Alionsín, Q.- Ob. Cit., pág. 107.

(14) Alonsín, Q.- Ob. Cit., pág. 111.

(15) Las naves $y$ aeronaves no son "Iugares" sino muebles, pese a que el derecho privado los reputa inmuebles para mejorar su condición patrimonial $y$ su negociabilidad.Ferrero, Raúl, "Derecho Constitucional", Lima, 1956.- pág. 86. 
al contrato de trabajo y deberían en consecuencia estar sometidos a la ley trancesa por ser ésta la ley que regía dicho contrato, por haberse celebrado en Francia. (16)

En cuanto se refiere a la forma del contrato, el principio "locus regit actum" está universa'mente aceptado. Refiriéndose al contrato de trabajo, Cabanellas, Lanfranchi y Krotoschin (17) nos dicen que se aplica la ley del lugar de la celebración en lo relativo a sus formas instrumentales.

Nuestro Código Civil en el art. XX del Título Preliminar establece que "la forma de los actos jurídicos $Y$ de los instrumentos se rige por la ley del lugar en que se otorgan..."

En el campo de los acuerdos internacionales, cabe citar el art. 39 del Tratado de Montevideo de 1889 y el art. 36 del Tratado de Montevideo de 1940 .

Sin embargo, es oportuno aclarar aquí, que el aspecto formal en el contrato de trabajo, es un elemento de relativa importancia, por cuanto aún en el caso de que el contrato fuese nulo por defecto de forma, el hecho del trabajo en sí es capaz de generar las obligaciones recíprocas que el acuerdo inválido es impotente.

Vinculadas con la labor de la O.I.T. resulta pertinente mencionar, a manera de ejemplo, las Convenciones sobre Contratos de Trabajo para Indígenas, Nos. 64 y 86, de 1939 y 1947, respectivamente, que adoptan este sistema.

\section{SISTEMA DE LA LEY DEL LUGAR DE LA EJECUCION DEL CONTRATO}

Este sistema considera que la ley competente para regir la relación laboral es aquella vigente en la localidad donde efectivamente se lleve $\alpha$ cabo la prestación de servicios.

El fundamento de este sistema reside en la índole territorial de la legislación de trabajo y en el caracter de orden público de muchas de sus disposiciones. Esta nota se pone de relieve cuando se encuentran comprometidas normas de policía del trabajo. El interés público, involucrado en dichas normas, destaca como elementos de conexión al trabajo en sí y al lugar de su ejecución, relegando todo otro criterio a un plano secundario. Ninguna legislación puede tener mayor interés en regular la relación laboral que la del Estado en cuyo territorio se desarrolla el trabajo. Las consecuencias tanto económicas como sociales que se derivan de este contrato afectan primordialmente al pais en donde surte sus efectos, es decir, en donde se ejecuta el trabajo.

Además, en el orden lógico, todo parece indicar que la ejecución del acto o contrato es lo más importante. Constituye la consecución de los ob-

(16) Romero del Prado, Ob. Cit., págs. 1007 y 1008. Ver: Revue de Droit International Privé, 1921, pág. 501 .

(17) Cabanellas, G.. "Tratado de Derecho Laboral", pág. 640; Ianfranchi, C., Ob. Cli., pág. 198; Kroloschin, E., Ob. Cit, pág. 915. 
jetivos deseados la realización del fin persiguido. De tal manera, la ley del lugar de la ejecución debe regular el contrato por ser cicho momento el más representativo de la relación.

Refuerza esie argumento, el hecho de que en la realidad, la relación laboral queda necesariamente sujeta, por lo menos parcialmente, a la ley del lugar de la ejecución. Ante esta circunstancia inevitable, conviene hacer extensiva la aplicación de la ley del lugar de ejecución a todo lo concerniente a la relación laboral, y apartar asi la posibililad de ciie sobro un mismo contrato recaigan dos o más legislaciones.

A mayor abundamiento, se subraya la particularidad de gue las autoridades administrativa.3 y judiciales competentes para conocer las controversias derivadas de la relación laboral suelen ser las del lugar donde se prestan servicios. Feliz coincidencia que asegura de esta manera la aplicación por parte de las autoridades requeridas de su propia lex fori.

Por otro lado, no deja de ser signilicativo que este sistema se haya generalizado. Practicamente todos los países de América han adoptado la territorialidad en materia de trabajo, comenzando por el Perú. según lo preceptuado por los arts. 46 y 47 del reglamento de la Ley 4916 . Aunque si bien es verdad que nuestro país adopta como excepción el sistema de la ley del lugar de la celebración, cuando dispone, en la úlíma parte del art. 47 en mención, quie para los efectos de la Ley 4916 "También se computarán los servicios prestados en el extronjero, cuando hayan sido contratodos en el Perú".

El Dr. García Gastañeta - pora citar un cutor nacional - refiriéndose a las consecuencias del contrato de trabajo, afirma que "las leves que las rigen tienen un imperio territorial forzoso" (18).

Krotoschin nos dice que "El principio de la territorialidad de las le. yes de trabcijo, tomando como concepto de conexión al locus executionis, es, en principio, reconocido universalmente". (19) "La lex loci executionis, encontrará, así, frecuente y justa aplicación, para todo cuanto concierne a aquello que podríamos llamar: la realización del contrato de trabajo en orden a sus dos principales obligaciones contrapuestas: el trabajo y el salario". (20).

Por su parie, el Código de Bustamante en su art. 198 dispone en fórmula escueta que "también es territorial la legislación sobre accidentes del trabajo y protección social del trabajador".

El Tratado de Montevideo de 1889 somele a todo derecho contractual, sin distinción, a la ley del lugar de cumplimiento del contrato. El tratado de Montevideo de 1940, en su art. 38, calificado - por el Dr. José Luis Bustamante y Rivero - como la fórmula que sin ser perfecta "es la más completa, elástica y científica" (21) establece en su parte final que "los contra-

(18) García Gastañeta, C. "Derecho Internacional Privado".-Lima, 1930. pág. 221.

(19) Kroloschin, E.- Ob. Cit., pág. 915.

(20) Lantranchi, C., Ob. Cit., pág. 199.

(21) Bustamante Y Rivero, "El Tratado de Derecho Civil Internacional de 1940". Monterideo, 1942, pág. 119 . 
los que versen sobre prestación de servicios se rigen: $\alpha$ ) Si recaen sobre cosas, por la del lugar en donde ellas existían al tiempo de su celebración; b) Si su eficacia se relaciona con algún lugar especial, por la de aquel en donde hayan de producirse sus efectos; c) Fuera de estos casos, por la del lugar del domicilio del deudor al tiempo de la celebración del contrato". Como se puede apreciar, los dos primeros incisos hacen referencia en realidad al principio de la lex loci solutionis. El último inciso establece una solución necesaria para aquellos casos en que no exista un lugar de ejecución inequívoca.

Igualmente, la Carta Internacional Americana de Garantías Sociales, aprobada en la Novena Conferencia Internacional Americana, celebrada en Bogotá, en el mes de abril de 1948, establece en su art. $2^{\circ}$ inc. e) que "los aerechos consagrados a favor de los trabajadores no son renunciables y las leyes que los reconocen abligan y benefician a todos los habitantes del territorio, sean nacionales o extranjeros".

Entre las Convenciones de la $\mathrm{O}$. I. T. también se cuentan algunas que consagran este sistema. Al respecto cabe mencionar entre otras las Convenciones Nos. 35, 36, 37, 38, 39 y 40, sobre seguridad social celebradas el año 1933. Entre estas, las Nos. 35, 37 y 39 se encuentran ratificadas por nuestro País.

Es interesante destacar que los instrumentos en referencia, al igual que la Convención sobre Trabajadores Fronterizos, celebrada por las potencias del Tratado de Bruselas (22) contemplan además, ciertos casos específicos para los cuales establecen un régimen especial; excepción que no desmiente a la regla general que consagran, sino que la confirman.

Pese a las razones expuestas, que sindican al sistema que nos ocupa como el más apropiado para regular la relación de trabajo, no es del caso ocultar los serios inconvenientes que le son anexos, los cuales determinan que este sistema para funcionar normalmente requiera: (23).

$1^{\circ}$.- Que el lugar de la ejecución del contrato sea en un sólo Estado. Si no fuera así, la lex loci solutionis aplicable no sería una sola. El contrato quedaría sometido de tal suerte a dos o más legislaciones, lo que importa caer en el defecto que hemos condenado.

$2^{\circ}$.- Que el lugar de ejecución sea conocido en el momento de la celebración. Si no fuera así, el contrato no se podría regir por la lex loci solutionis en dicho momento. Resulta absurdo exigir que se aplique al contrato la ley de un lugar que se ignora. En este supuesto se desmembraría el contrato ya que al instante de celebrarse el mismo habría que sujetarlo necescriamente $\alpha$ alguna ley, y luego, $\alpha$ momento de su ejecución, aplicarle la ley del lugar donde se presten los servicios.

$3^{\circ}$.- Que el lugar de ejecución no cambie con posterioridad a la celebración del conirato. Esto se comprende fácilmente. Lo contrario equi-

(22) 17 de Abril de 1950.- Ver: Industry and Labor, Vol. X, No 5 Suplemento sobre Migraciones, pág. 89.

(23) Síquese a Altonsín, Q., Ob. Cit., pág. 117 
vale a decir que el contrato puede regirse sucesivamente por más de una legislación, lo que hemos calificado de inaceptable.

"Esta objeción pone al sistema de la lex loci solutionis en un dilema: asegurar la unidad de la ley a costa del sacrificio de los casos en que su aplicación resulte inadecuada, o asegurar la aplicación de la ley adecuada a costa del sacrificio de la unidad de la ley". (24).

Quienes se aferran a este sistema pretenden salvar estas objeciones ideando un complicado juego de presunciones legales, destinadas a "la relación de trabajo - al menos jurídicamente. Pero este intento fracasa por artificioso, pues se aparta de la realidad, precisamente estando de por medio el Derecho de Trabajo, disciplina jurídica realista por excelencia.

En conclusión. El sistema de la ley del lugar de ejecución del con. trato resulta el más adecuado a la naturaleza de la relación de trabajo. Sin embargo, por sí solo no logra sortear todas las situaciones que se presentan en Derecho Internacional Privado del Trabajo. Por ello, creemos que la solución más satisfactoria se logra mediante la combinación de más de un sistema, tomando como base el de la lex loci solutionis. Así, para los casos en que el trabajo se realice de manera permanente, en un lugar predeterminado, la ley del lugar de la prestación deviene acertada. Pero cuando el trabajo ha de ejecutarse en varios países alternativamente, en forma pasajera, sin que se pueda por ello localizar el contrato en un lugar preciso, entonces procede aplicar la ley del domicilio de la empresa, La misma solución se recomienda cuando el trabajador de manera ocasional y temporal deba trasladarse al extranjero.

No falta tampoco quier recomiende, en estos últimos casos, aplicar la ley del lugar de la celebración, o la ley personal, cuando es común a las partes.

\section{SISTEMA DE LA LEY MAS FAVORABLE AL SERVIDOR}

Este sistema propugna que entre las muchas legislaciones susceptibles de aplicarse a una relación laboral, resulta competente la que más beneficie al trabajador.

Nos dice Cabanellas, refiriéndose $\alpha$ los efectos de la ley laboral en el espacio que "Tanto en lo relativo a la celebración del contrato como a las condiciones del mismo, a su ejecución y a las responsabilidades inherentes, se adopta las formas de legislación más favorables al trabajador entre las tenidas en cuenta al realizar el contrato". (25).

El fundamento de este sistema descansa en el aspecto tutelar que caracteriza ideológicamente al Derecho de Trabajo. Las normas laborales constituyen un mínimo de garantías sociales protectoras del asalariado. Como quiera que dicho mínimo puede ser superado por la voluntad de las partes, no hay inconveniente para que dicha mejora se logre mediante la

(24) Alfonsín Q., Ob. Cit., pág. 125.

(25) Cabanellå. G.- Ob. Cit.- pág. 640. 
aplicación de la ley extranjera. Piénsese que los contratantes pueden alconzar el mismo fín, copiando en forma detallada las disposiciones pertinentes de la ley foranea, en vez de remitirse simplemente a ella.

Es principio consagrado que la legislación de trabajo es territorial, y como tal se aplica la ley del Estado en cuyo suelo se prestan los servicios. Pero se estima que la territorialidad no puede imponerse en perjuicio del trabajador. La propia naturaleza del Derecho de Trabajo lo impide.

De aceptarse este sistema, cabe preguntarse si ha de aplicarse la legislación extranjera más favorable al asaloriado en su conjunto, o fraccionariamente. La respuesta para algunos (26) es que el ordenamiento debe contemplarse en su conjunto, y aplicarse como un todo indivisible.

Otros, en cambio, adoptan la solución opuesta. Así De la Cueva y Hall Lloreda (27) afirman que la ley extranjera se aplica en todo en cuanto mejore al derecho local en provecho del servidor, pero tiene que ceder ante la ley nacional cuando viola los mínimos por ella establecidos. Se dibuja, de tal suerte, un mosaico conformado por los dispositivos más avanzados de todas aquellas legislaciones concurrentes.

En el primer caso, se objeta que resulta sumamente difícil para el Juez determinar entre dos o más legislaciones cual es la más tavorable al servidor. En el segundo caso, el reparo es más grave, pues a la dificultad de considerar, esta vez, desarticuladamente, cada uno de los elementos de los diversos derechos, se añade la circunstancias de que la relación de trabajo quedaría sujeta, al mismo tiempo, a normas provenientes de distintas legislaciones.

Pese a estas observaciones, una interpretación de las normas mexicanas permite al profesor De la Cueva afirmar que este sistema es seguido por el Derecho Mexicano de Trabajo.

Similar posición adopta el $D_{r}$. García Gastañeta, en cuanto al Perú se refiere, al sostener que "No habría sin embargo inconveniente en aplicar la ley extranjera siempre que ella fuera más favorable al damnificado" (28).

En abstracto, la regla más favorable al servidor, principio netamente de Derecho del Trabajo, puede aplicarse satisfactoriamente en derecho interno; vale decir, cuando esta rama jurídica actúa independientemente y dentro de un sólo campo legislativo. Distinto es el caso en Derecho Internacional Privado del Trabajo, en que tanto los principios de Derecho de Trabajo, como los de Derecho Internacional Privado Común, convergen hacia un mismo fín. En Derecho Internacional Privado del Trabajo hay que contemplar, por igual, los exigencias propias de uno y otro Derecho y tratar de hallar la armóníca relación de ambos. No sería adecuado sacrifi-

(26) Ver en este sentido: Gaete Berrios, Ob. Cit.. pág. 116 ₹ Krotoschin, E., Ob. Cit., pág. 53.

(27) Cueva. M.. D. M. del T., pág. 399. - Hall Lloreda. C., Ob. Cit.. pág. 148.

(28) García Gastañeta, C.- Ob. Cit., pág. 221. 
car totalmente el tecnicismo del Derecho Internacional Privado en aras del principio "pro-operario", y viceversa.

Por otro lado, la aplicación arbitraria del sistema de la ley más favorable al servidor puede conducir a franca injusticia, acumulando sobre el empleador una carga de beneficios sociales demasiado onerosa de soportar y muchas veces imprevista. Estas circunstancias, pueden tener efectos contraproducentes en el comercio internacional y obstaculizar, en vez de favorecer, el desarrollo de las relaciones jurídico-laborales en la sociedad universal.

Por ello, estimamos, que la ley más favorable al servidor como sistema no es conveniente. Pero no descartamos del todo las ventajas que de él pueden derivarse. Creemos que las mismas se aprovecharían debidamente a través de la noción de los derechos adquiridos, respetando los límites y condiciones fijados al estudiar dicha institución. 